\title{
Localization and quantitation of macrophages, mast cells, and eosinophils in the developing bovine mammary gland ${ }^{1}$
}

\author{
K. L. Beaudry, C. L. M. Parsons, S. E. Ellis, ${ }^{2}$ and R. M. Akers ${ }^{3}$ \\ Department of Dairy Sciences, Virginia Polytechnic Institute and State University, Blacksburg 24061
}

\begin{abstract}
Prepubertal mammary development involves elongation and branching of ducts and stromal tissue remodeling. This process is highly regulated and in mice is known to be affected by the presence of innate immune cells. Whether or not such immune cells are present or involved in bovine mammary development is unknown. For the first time, we determined the presence, location (relative to mammary ductal structures), and changes in numbers of eosinophils, mast cells, and macrophages in prepubertal bovine mammary tissue, and evaluated the effects of age, ovariectomy, and exogenous estrogen on numbers of each cell type. Chemical stains and immunofluorescence were used to identify the 3 cell types in formalin-fixed, paraffin-embedded mammary tissue from prepubertal female calves from 3 archived tissue sets. The ontogeny tissue set included samples of mammary tissue from female calves $(\mathrm{n}=4 / \mathrm{wk})$ from birth to $6 \mathrm{wk}$ of age. The ovary tissue set contained samples from ovary intact and ovariectomized heifers allowing us to investigate the influence of the ovaries on immune cells in the developing mammary gland in prepubertal heifers. Nineteen animals were intact or ovariectomized $30 \mathrm{~d}$ before sampling; they were 90, 120, or $150 \mathrm{~d}$ old at the time of sampling. A third tissue set, the estrogen set, allowed us to determine the effect of exogenous estrogen on innate immune cells in the gland. Eosinophils were identified via Luna staining, mast cells by May-Grunwald Giemsa staining, and macrophages with immunofluorescence. Key findings were that more eosinophils and mast cells were observed in near versus far stroma in the ontogeny and ovary tissue sets but not estrogen. More macrophages were observed in near versus far stroma in ontogeny animals. Eosinophils were more abundant in the younger animals, and fewer
\end{abstract}

Received June 16, 2015.

Accepted September 15, 2015.

${ }^{1}$ This work performed by S. E. Ellis was partially supported by the US National Science Foundation while working at the Foundation. The views expressed in this article do not necessarily reflect those of the National Science Foundation or the United States Government.

${ }^{2}$ Current address: Biological Sciences Directorate, National Science Foundation, 4201 Wilson Boulevard, Arlington, VA 22230.

${ }^{3}$ Corresponding author: rma@vt.edu macrophages tended to be observed in ovariectomized heifers as compared with intact heifers and estrogen treatment resulted in a reduction in cell numbers. In summary, we show for the first time that innate immune cells are present in prepubertal bovine mammary tissue, localization varies by immune cell type, and abundance is related to proximity of epithelial structures and physiological state. We suggest a likely role for these cells in control of bovine mammary growth and ductal development.

Key words: mammary development, bovine, macrophage, eosinophil, mast cell

\section{INTRODUCTION}

Bovine mammary development during the peripubertal period is important for future milk production (Tucker, 1981). During this time the bovine mammary gland develops a ductal system which extends into the fat pad and provides a framework for future lobulo-alveolar development (Sheffield, 1988; Akers, 2002). The bovine mammary ductal system, which develops during this period, arises as terminal ductule lobular units, which are clusters of ductules arising from larger ducts (Hovey et al., 1999). In contrast, the mouse mammary gland develops through extension of ducts at terminal end buds (TEB; Williams and Daniel, 1983; Sheffield, 1988). In the mouse, the TEB is the site of the majority of epithelial cell proliferation, whereas proliferation in the developing bovine ductal system occurs along the length of the extending duct (Sheffield, 1988; Silberstein, 2001; Capuco et al., 2002).

The stromal area surrounding the developing ducts provides a three-dimensional matrix for development of vasculature and lymph systems and also acts to mediate local responses to hormones and growth factors (Hovey et al., 1999). In the case of the stroma surrounding the mouse TEB, innate immune cells also concentrate near the TEB. These cells have been shown to be required for normal mouse mammary development (Gouon-Evans et al., 2000). Irradiation studies demonstrate severe impairment of mammary ductal structures in developing mouse mammary glands when innate immune cells are absent. The changes in mouse 
mammary ductal structure were rescued after bone marrow transplant (Gouon-Evans et al., 2000). Of the innate immune cell types, 3 have been identified to play crucial roles in mouse mammary development. Macrophages, which are generally considered professional phagocytes, are thought to be heavily involved in matrix remodeling. They affect the elongation and shape of the duct during development (Reed and Schwertfeger, 2010; Coussens and Pollard, 2011). In mice, removal of the macrophage recruitment factor, colonystimulating factor 1 , reduces macrophage numbers and impairs mammary ductal development (Gouon-Evans et al., 2000). Eosinophils, which mediate immune responses through cytokine release during wound healing, are also important in mouse mammary development (Reed and Schwertfeger, 2010; Coussens and Pollard, 2011). Reduction in eosinophils through reduction in their attractant, eotaxin, results in creation of a ductal tree with fewer branches (Gouon-Evans et al., 2000). Finally, mast cells, which are present in the mammary stroma at all developmental stages, contain factors in their granules which can influence local immune response and, thus, mammary development (Reed and Schwertfeger, 2010). Deficiency of mast cells during the peripubertal period leads to fewer ductal structures and TEB (Lilla and Werb, 2010). Each of these 3 innate immune cell types - macrophages, eosinophils, and mast cells - have unique but apparently necessary roles in mouse mammary development. Each immune cell type also has specific localization characteristics in relation to the TEB: macrophages align with collagen fibers along the neck region (Ingman et al., 2006), eosinophils locate at branch points (Reed and Schwertfeger, 2010; Coussens and Pollard, 2011), and mast cells are found clustering at the head of advancing TEB (Lilla and Werb, 2010).

Hormonal changes during the peripubertal period induces the onset of allometric mammary growth ( Li et al., 2006) and ovariectomy of animals at an early age leads to lower mammary tissue volume and a reduction in ductal development in heifers (Purup et al., 1993). Estrogen, in particular, appears to be an important hormonal regulator of mammary development, with the ability to stimulate proliferation (Li et al., 2006). Estrogen-related signals have also been linked to the recruitment of immune cells in the mammary gland, with estrogen possibly regulating cytokine production (Gouon-Evans and Pollard, 2001; Reed and Schwertfeger, 2010). This provides a link between the hormonemediated changes in the development of the mammary gland and the presence of immune cells.

The present study used archived tissue samples to investigate the abundance and location (relative to epithelial structures) of 3 innate immune cell types- macrophages, eosinophils, and mast cells - in the developing bovine mammary gland. We also evaluated the effect of age, ovariectomy, and exogenous estrogen on the abundance and localization of these immune cells in the developing bovine mammary gland.

\section{MATERIALS AND METHODS}

\section{Tissue Samples}

Samples for the ovary set $(\mathbf{O} / \mathbf{I})$ were obtained from a previous study (Velayudhan et al., 2012). Briefly, 24 Holstein heifers were purchased after weaning and fed heifer grower with mixed forage pasture and highquality forage. After a 1-wk adaptation period, heifers were assigned to a $2 \times 3$ factorial design treatment design. The first factor was ovariectomy $(\mathrm{n}=12)$ or ovary intact $(\mathrm{n}=12)$, with the second factor age at which surgery was performed (2, 3, or 4 mo). Surgery to remove ovaries in ovariectomy calves was performed laparoscopically, and ovary intact heifers had their ovaries palpated during a sham operation. Animals were euthanized humanely $30 \mathrm{~d}$ after surgery and mammary tissue was harvested immediately. Tissue for histology was taken from the left front quarter of the udder and fixed in $10 \%$ buffered formalin. Ovariectomy was confirmed at slaughter, which resulted in the exclusion of 2 animals that were found to have ovarian fragments with follicles and 2 other animals that had insufficient mammary parenchyma for analysis. Tissues were fixed, dehydrated, cleared, infiltrated, embedded in paraffin, and sectioned following standard procedures (Velayudhan et al., 2012).

Samples for the ontogeny (ONT) set of tissues were obtained from a study conducted at Clemson University (Clemson, SC). Briefly, neonatal Holstein heifers ( $\mathrm{n}=$ 4/age) were euthanized and mammary tissue sampled within $12 \mathrm{~h}$ of birth (d 0) and at d 7, 14, 21, 28, 35, and 42 of age. Calves were fed commercial milk replacer and starter ration during the study.

Samples comprising the estrogen $(\mathbf{E} / \mathbf{C})$ tissue set were also obtained from a previous study (Geiger et al., 2015). Briefly, calves were obtained within the first week of life and started immediately on an accelerated milk replacer diet. Animals were administered an estrogen implant $(\mathrm{n}=6)$ or placebo implant (control group, $\mathrm{n}=4$ ) when weaned at 8 wk of age. Animals were humanely slaughtered at $10 \mathrm{wk}$ of age and the mammary gland was removed immediately. The right front quarter was formalin fixed and tissue samples were processed as described earlier.

The use of animals to generate tissue samples in all previous experiments was approved by IACUC at Virginia Tech or Clemson University. All tissue samples 
were processed and embedded in paraffin before being sectioned to $5 \mu \mathrm{m}$ on a microtome (HM 340E, Microm, Walldorf, Germany). The sections were floated in a warm water bath $\left(37-42^{\circ} \mathrm{C}\right)$ to remove wrinkles and mounted on a charged slides (SuperfrostPlus, VWR, Radnor, PA), with 3 to 5 sections per slide. Slides were placed on a slide warmer after draining to thoroughly dry. Slides for both visible and immunofluorescent staining were deparaffinized and rehydrated in the same manner. Deparaffinization was achieved by sending slides through 2 baths of aliphatic xylene substitute (VWR) for $5 \mathrm{~min}$ each. Sections were then rehydrated through a series of ethanol baths and a final distilled water bath. Slides were taken directly from the distilled water bath for the following procedures.

\section{Immunofluorescence}

Rehydrated sections were outlined with a hydrophobic barrier pen (PAP pen, Ted Pella Inc., Redding, CA) then subjected to a $0.125 \%$ trypsin digest (Ultravision trypsin, Thermo Fisher Scientific, Suwanee, GA) at $37^{\circ} \mathrm{C}$ for $10 \mathrm{~min}$ for antigen retrieval. Sections were washed $3 \times 2$ min in $1 \times$ Dulbecco's PBS, calcium and magnesium free, at $\mathrm{pH}$ 7.4. Sections were blocked with CAS-Block (Invitrogen, Grand Island, NY) for $30 \mathrm{~min}$ at room temperature. Primary antibody, (a macrophage maker; anticalprotectin; cat \#ab22506, Abcam, Cambridge, MA) was diluted in CAS-Block (Invitrogen; 1:100) and $100 \mu \mathrm{L}$ was applied to sections. Negative control samples received CAS-Block alone. Slides were incubated overnight at $4^{\circ} \mathrm{C}$ in a humidified chamber. Primary antibody was aspirated and sections were washed 3 times in $1 \times$ PBS for 5 min. A goat antimouse IgG secondary antibody conjugated to Alexa Fluor 488 (Invitrogen), as supplied by the manufacturer was diluted in CAS-Block (1:200), and $100 \mu \mathrm{L}$ was applied to sections. The secondary antibody solution was centrifuged for $10 \mathrm{~min}$ at $10,000 \times \mathrm{g}$ at $4^{\circ} \mathrm{C}$ to remove aggregates before use, and $100 \mu \mathrm{L}$ of this solution was pipetted onto all sections. Sections were allowed to incubate for one hour at room temperature. Unbound secondary antibody solution was aspirated and sections were washed 3 times in $1 \times$ PBS for $2 \mathrm{~min}$. After the last wash, the PAP pen markings were removed with xylene substitute and slides were rinsed with $1 \times$ PBS before being cover-slipped using the SlowFade Gold mounting medium containing DAPI (4',6-diamidino2-phenylindole), which binds to DNA (Invitrogen). Slides were allowed to sit for $20 \mathrm{~min}$ before visualization. Photomicrographs were acquired with a Nikon Eclipse E600 (Nikon Instruments Inc., Melville, NY) microscope mounted with a Nuance RX (CRI, Woburn,
MA) camera. Images of Alexa Fluor 488 were acquired with an emission range of 520 to $550 \mathrm{~nm}$. Macrophages were identified in pictures (Figure 1) as positive staining cells with a nonlobulated nucleus.

\section{Modified Luna Stain for Eosinophils}

Eosinophils can be identified by their distinctive nuclear shape as well as the granules present in their cytoplasm (Figure 1). Rehydrated sections were stained first in Weigert's Iron Hematoxylin (kit, ENG Scientific, Clifton, NJ) for $5 \mathrm{~min}$ and blued in $0.5 \%$ lithium carbonate (Sigma-Aldrich, St. Louis, MO) until the sections noticeably changed color and were rinsed with tap water. This was followed with a 3-min staining step in aqueous 1\% Biebrich scarlet (Ponceau BS, Sigma-Aldrich). Slides were then differentiated in $1 \%$ hydrochloric acid in $70 \%$ ethanol for 5 to 7 dips. Sections were then rinsed in running tap water until slides turned a noticeable purple-blue color (about 2 min). Sections were dehydrated through graded series of ethanol and 2 changes of histological grade xylene (Thermo Fisher Scientific) before mounting with a resinous medium (Permount, Thermo Fisher Scientific).

\section{May-Grunwald Giemsa Staining for Mast cells}

The May-Grunwald Giemsa staining protocol stains most immune cells with several identifying characteristics. The nuclei stain blue and mast cell granules undergo a metachromatic reaction to turn purple. The colors of these stains are very $\mathrm{pH}$ sensitive. To achieve staining which identified mast cells, a pH-6.3 sodium phosphate buffer (0.06 molar) was used. Rehydrated sections were flooded with a working May-Grunwald stain solution and allowed to incubate 6 min with occasional agitation. The working May-Grunwald stain solution was prepared by a 1:1 dilution of stock May-Grunwald stain (Harleco for EMD Millipore, Darmstadt, Germany) in the pH-6.3 sodium phosphate buffer. The excess stain was rinsed off slides with PBS and slides were flooded with working Giemsa stain solution for 13 min with agitation. Working Giemsa stain was prepared by diluting the stain stock (Harleco for EMD Millipore; 1:20) in the pH-6.3 phosphate buffer; slides were then rinsed with PBS. Sections were differentiated by dipping slides in $0.25 \%$ acetic acid solution 8 to 10 times and then rinsed again in buffer. The slides were rinsed in distilled water before air drying. After air drying, slides were cleared in xylene, mounted, coverslipped using Permount (Thermo Fisher Scientific), and allowed to cure before viewing. Mast cells were identified as cells with a blue nucleus and purple granules (Figure 1). 


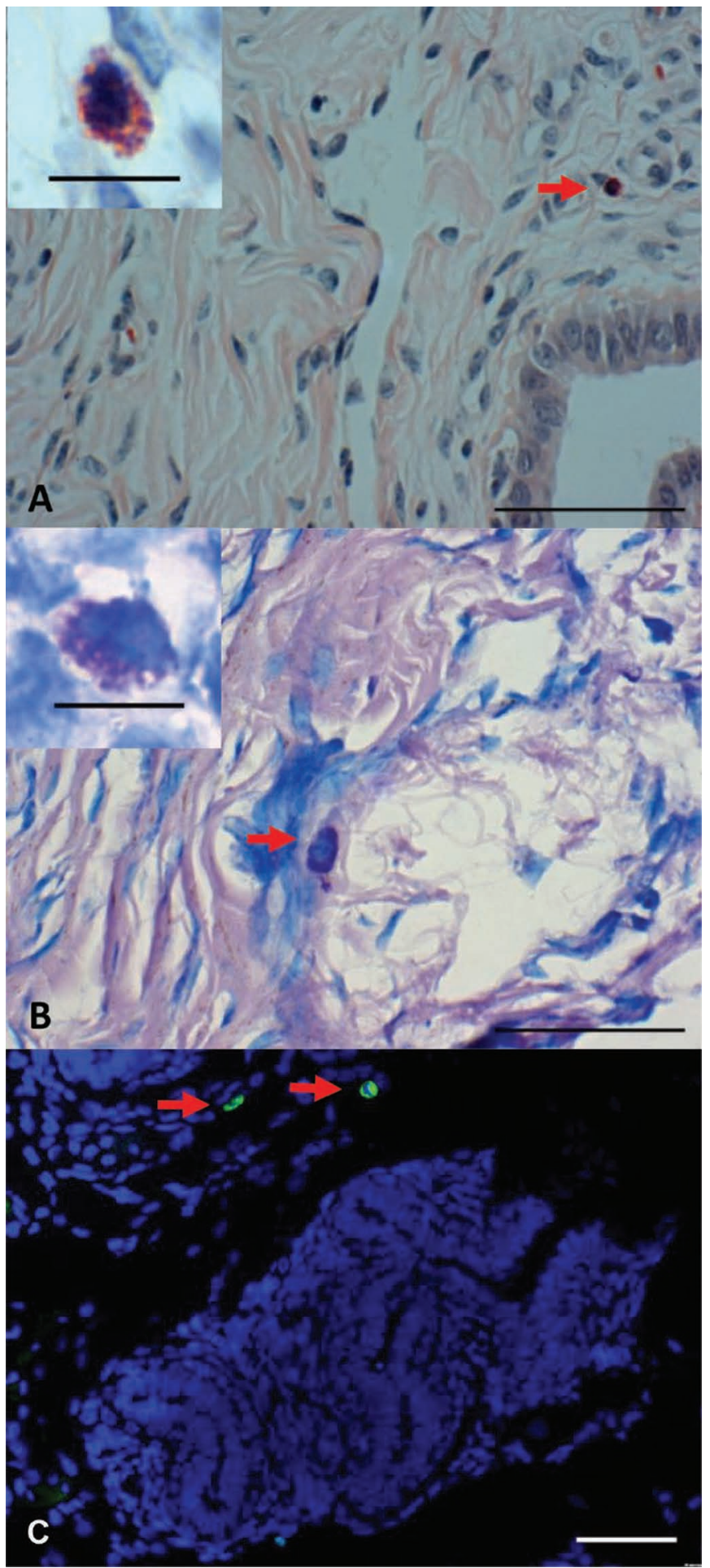

Figure 1. (A) Luna stain for eosinophils. Arrow indicates an eosinophil with dark pink or red granules and blue nucleus. Inset illustrates cell detail. (B) May-Grunwald Giemsa stain for mast cells. Arrow indicates a mast cell with distinctive purple granules and blue nucleus. Inset illustrates cell detail. (C) Immunofluorescent stain using antimacrophage antibody. Green indicates macrophages (arrows); blue is a DAPI (4',6-diamidino-2-phenylindole) counterstain. Scale bars on large images represent $50 \mu \mathrm{m}$; scale bars on insets represent $10 \mu \mathrm{m}$. Color version available online.

\section{Cell Quantification}

For each animal, one slide was stained using each method described above. From these, 40 photos were taken, ideally from a single section and, if not, from nonadjacent sections to avoid counting a cell twice. All pictures used for counting were taken on an Olympus microscope with $40 \times$ objective lens (Olympus America Inc., Center Valley, PA) using a Q Color III digital camera (Olympus America Inc.). Half (20) of the pictures taken for each animal contained epithelium and half (20) were stroma with no epithelium. Pictures were taken in a generalized grid fashion within the confines of stroma or epithelial containing regions to ensure no overlap between pictures and coverage of a representative area. Pictures were then transferred to ImagePro Plus 7.0 (Media Cybernetics, Rockville, MD) for processing. All pictures were spatially calibrated and relevant areas were measured using the software, with cell counts (cells per outlined tissue area) also being taken at this time.

The cell counts are divided into 2 distinct groups: cells that were determined to be from far stromal or cells which were determined to be from near stromal tissue regions. The distinction between far and near stromal was determined by visual examination (Figure 2). Far stroma was generally more diffuse and contained more fibrous tissue as well as adipose. Near stroma was generally more dense, and within 100 to $150 \mu \mathrm{m}$ from the nearest epithelium. Areas were measured using Image-Pro Plus software and cells per area counted. To obtain the values for statistical analysis, the areas of all 20 pictures for an animal (either stromal or epithelial containing) were summed, as were the cells that fell within the near or far stromal regions. The cell number was then divided by the area to get cells per micrometer squared, and the values multiplied by $1 \times$ $10^{6}$ to express values as cells per millimeter squared of tissue area.

\section{Statistical Analysis}

Data were analyzed in JMP (SAS institute Inc., Cary, NC). All 3 cell types were evaluated with the same model; however, models differed between tissue sets. For the O/I set, the model included main effects of treatment, age, and location, as well as animal within treatment and age as a random effect. For the ONT set, the model included main effects of age and location as well as animal within age as a random effect. Finally, for the E/C set, the model included main effects of treatment, location, and interactions with calf within treatment as a random effect. Differences were determined to be significant if $P<0.05$, whereas $P<$ 


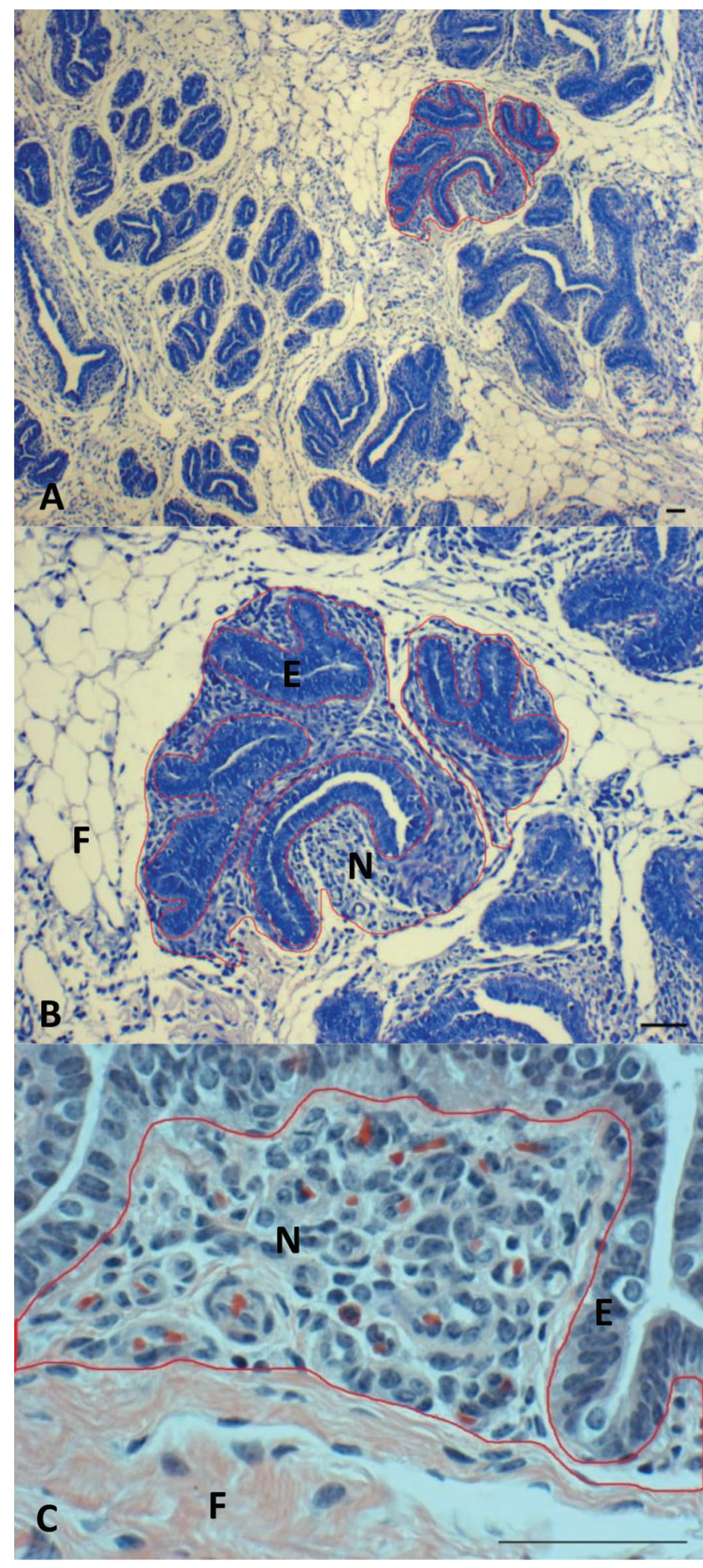

Figure 2. Examples of near (N) stroma, far (F) stroma, and epithelium (E) in mammary tissue at low (A), moderate (B), and higher (C) magnification. Images were collected initially using $4 \times, 10 \times$, and $40 \times$ objective lens. Scale bar represents $50 \mu \mathrm{m}$. Pictures are of tissue sections stained with May-Grunwald Giemsa (A and B) and Luna stains (C). Color version available online.
0.1 was considered to be a trend. Data are presented as least squares means \pm standard error of the mean.

\section{RESULTS AND DISCUSSION}

\section{Macrophages}

We observed macrophages in mammary tissue from all 3 tissue sets. We observed more macrophages in the near versus far stroma locations with 5 times as many macrophages in near versus far stroma in the ONT tissue set and a difference of over 4 fold in the E/C tissue set $(P=0.0001$ and $P=0.0004$, respectively). There was also a tendency for more macrophages in near versus far $(P=0.083)$ stromal areas in calves from the $\mathrm{O} / \mathrm{I}$ set (Figure 3 ). We found no significant effects of treatment $(\mathrm{O} / \mathrm{I}, \mathrm{E} / \mathrm{C})$ or age $(\mathrm{ONT})$ related to macrophages; however, a tendency for fewer macrophages after ovariectomy $(P=0.081)$ was noted. Our finding of more cells in the near versus far stroma suggests that macrophages do indeed cluster near developing ductal structures. This is similar to work demonstrating macrophages preferentially clustering around developing TEB in mice (Gouon-Evans et al., 2000). The larger numbers of macrophages we noted in the near stromal tissue areas indicate a preferential location for the macrophages within the developing bovine mammary gland.

The stromal microenvironment, which contains connective tissue and blood vessels as well as various cell types including immune cells, is important to ductal development in the mammary gland (Cunha and Hom, 1996). Macrophages in the mouse mammary gland are involved in organization of the collagen fibers, aid in the maintenance of the structure of the TEB (Ingman et al., 2006), and are generally found at the neck region of the TEB (Gouon-Evans et al., 2000). The mouse TEB provides a convenient orientation point, and is also the location of the proliferating cells which drive ductal growth forward (Macias and Hinck, 2012). As developing bovine ducts have proliferating cells along their length (Capuco et al., 2012), it is reasonable to expect a less-defined location for clustering of macrophages in the bovine. Therefore, clustering of cells in the near stromal location close to the developing structures containing proliferating cells is similar to the clustering of macrophages near the proliferating TEB in the mouse (Ingman et al., 2006). Mice lacking in macrophages through a homozygous recessive mutation typically have delayed TEB formation as well as organizational changes, with some TEB migrating in a lateral direction or away from the tip of the fat pad (GouonEvans et al., 2000). A deficiency in macrophages has also been shown to change the shape of the TEB, caus- 
A

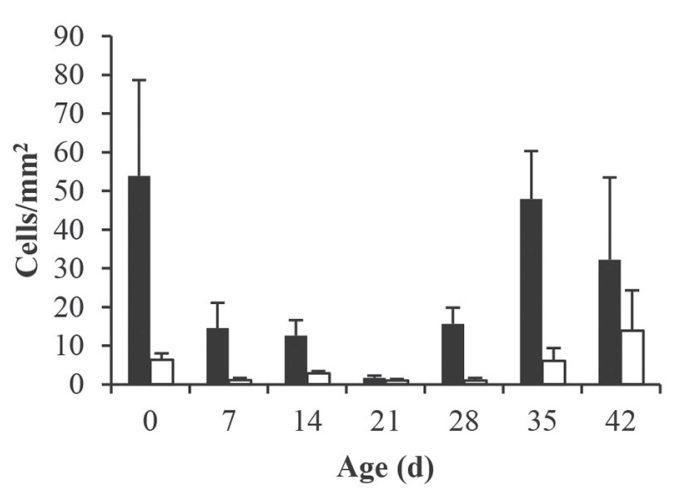

C $\quad \mathbf{E} / \mathbf{C}$

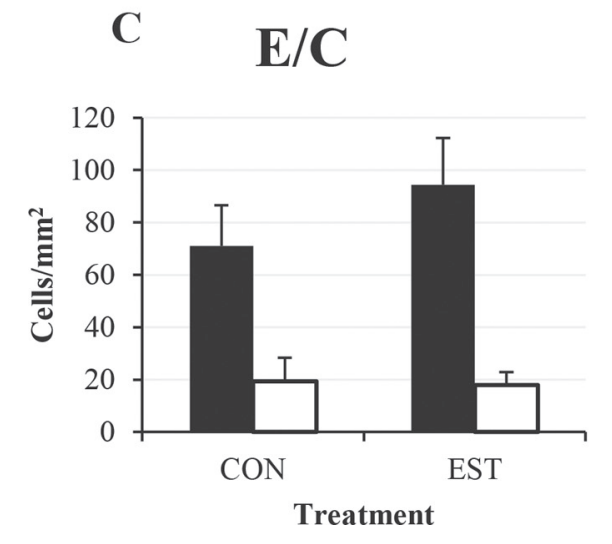

B

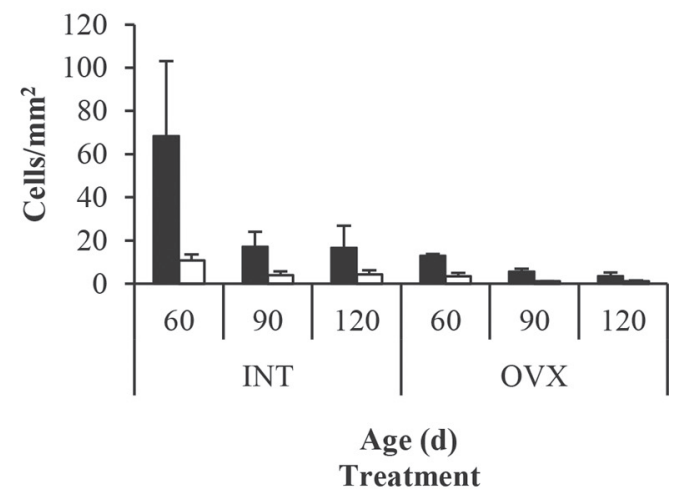

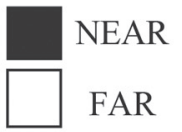

Figure 3. Significantly more macrophages were observed in the near (black bars) versus far (white bars) stromal areas in ontogeny (ONT; panel A) and estrogen $(\mathrm{E} / \mathrm{C}$; panel $\mathrm{C})(P=0.0001$ and 0.0004 , respectively). There was a tendency for a reduction after ovariectomy $(P=$ $0.081)$ and location $(P=0.083)$ effect (greater in near vs. far) in the ovary $(\mathrm{O} / \mathrm{I})$ tissue set (panel B). No other significant effects were observed.

ing them to be shorter and rounder (Ingman et al., 2006). Overall, these findings suggest an important role for macrophages in the organization of the developing ductal structure in the mouse mammary gland.

The presence and location of the bovine macrophages observed in the current study suggests that they are involved in bovine mammary development. Considering the differences in the pattern of development between bovine and murine mammary glands, our findings support the idea that bovine mammary macrophages cluster in areas of high cell proliferation, as seen in mice.

In the mouse gland, Gouon-Evans et al. (2000) observed macrophages around ductal structures before the appearance of TEB; however, they were at a lower density compared with those found later in postnatal mammary development. The tendency for few macrophages after ovariectomy may relate to the known role of estrogen in bovine and murine mammary ductal development (Li et al., 2006; Macias and Hinck, 2012), but no significant effect of estrogen treatment was observed. It is noteworthy that the abundance of macrophages was numerically greater in near stroma of estrogen-treated calves than in placebo-treated calves (Figure 3). Immune cells within the mammary gland of rodents have been shown to be modulated by ovarian hormones (Reed and Schwertfeger, 2010), as the number of macrophages fluctuate during the estrous cycle in rodents (Chua et al., 2010).

Although mouse mammary development and the involvement of immune cells have been well characterized, the presence and involvement of immune cells has yet to be described in the bovine. Further longitudinal studies will be required to investigate the important timing component that we were unable to resolve in our study. Regardless, our results demonstrated the presence of macrophages in the developing bovine mammary gland. We also showed that there are more macrophages per millimeter squared in the near versus far epithelium, suggesting that they are clustering close to the developing ductal structures. 
A

ONT

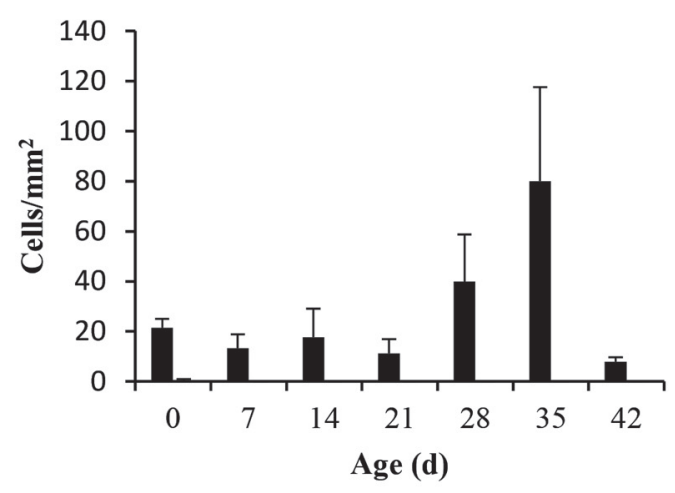

C

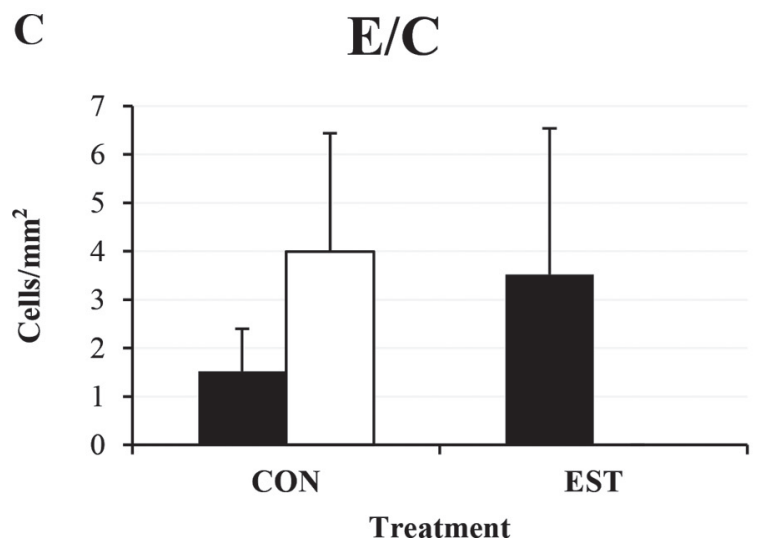

B

O/I

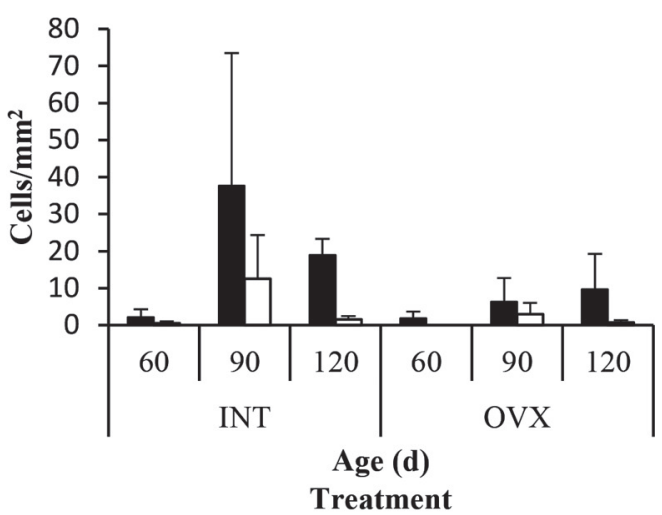

NEAR

FAR

Figure 4. More eosinophils were observed in the near (black bars) versus far (white bars) stroma in ontogeny (ONT; panel A) and ovary $(\mathrm{O} / \mathrm{I}$; panel $\mathrm{B})$ sets $(P=0.0004$ and 0.038 , respectively). There was a tendency for an effect of age in the ONT set $(P=0.08)$. No significant effects of treatment were observed in the estrogen $(\mathrm{E} / \mathrm{C}$; panel $\mathrm{C})$ set of tissues.

\section{Eosinophils}

We observed eosinophils in all 3 sets of animals. We measured more eosinophils in the near versus far tissue locations in both the ONT tissue set $(P=0.0004$, with an overall mean of 28.1 cells $/ \mathrm{mm}^{2}$ in the near and 0.07 cells $/ \mathrm{mm}^{2}$ in the far stroma) and in the $\mathrm{O} / \mathrm{I}$ tissue set $\left(P=0.038\right.$, with 13.5 cells $/ \mathrm{mm}^{2}$ in near compared with 3.5 cells $/ \mathrm{mm}^{2}$ in the far stroma; Figure 4). However, no significant effect of location was noted in the estrogen-treated calves (Figure 4). The observation of many more eosinophils within the denser area of stroma close to the developing epithelium and near absence of eosinophils in far stroma in ONT animals strongly suggests very distinct clustering of eosinophils close to the developing ductal structures in these animals. Abundant eosinophils have been observed in specific areas around developing ductal structures in the mouse mammary gland (Gouon-Evans et al., 2000). These researchers also demonstrated that removing locally produced eotaxin reduced recruitment of eosinophils to the TEB in the mouse mammary gland. Local stromal tissue production of eotaxin could explain the differences we observed in eosinophil numbers between near and far stromal areas in the developing bovine mammary gland. The abundance of eosinophils in the near stroma compared with the far stroma in the bovine suggests that eosinophils may have similar roles in development of bovine and murine mammary glands

No significant effect of treatment or age on eosinophil number was observed; however, we did note a trend for the effect of age $(P=0.081)$ in the ontogeny set. The greatest number of eosinophils was observed at d 14 . In mice, the transcript levels of eotaxin, a specific and powerful eosinophil attractant, increase around the time the TEB appear during development (Gouon-Evans et al., 2000). Although eosinophils were not enumerated in the reported study, an increase in eotaxin would be expected. Though we did not observe a significant age effect, the presence of this trend warrants further exploration. 


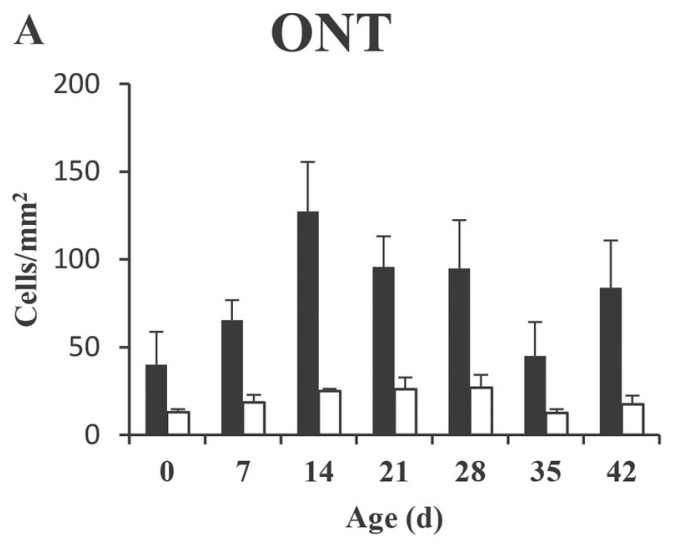

$\mathrm{C} \quad \mathrm{E} / \mathrm{C}$

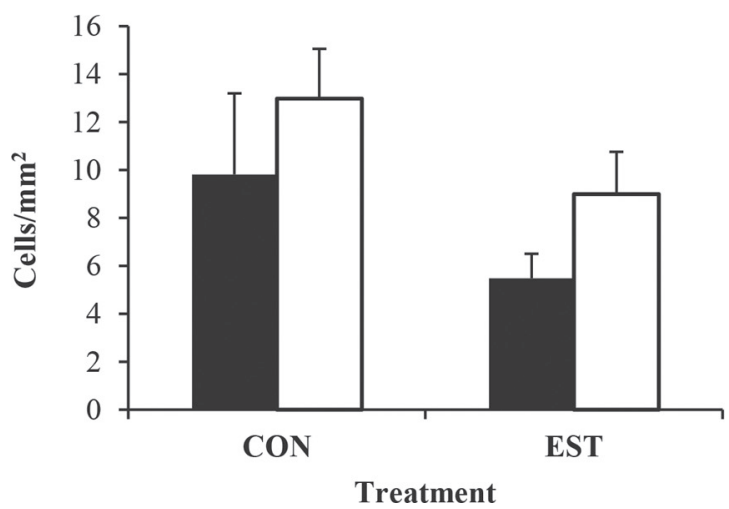

B $\quad \mathbf{O} / \mathbf{I}$

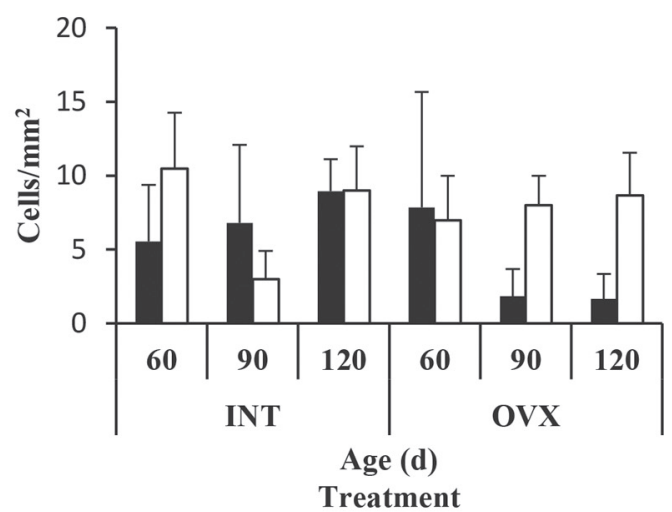

Figure 5. More mast cells were observed in the near (black bars) versus far (white bars) in the ontogeny $(\mathrm{ONT})$ set $($ panel A, $P=0.0004)$. There was also a trend for an effect of age in the ONT set $(P=0.0824)$. There were no significant effects in the ovary $(\mathrm{O} / \mathrm{I})$ set $($ panel B). There was a tendency for fewer mast cells after estrogen treatment strong $(\mathrm{E} / \mathrm{C})$ set (panel $\mathrm{C}, P=0.076)$, but no effect of location (near vs. far).

\section{Mast Cells}

We also observed mast cells in mammary tissue from all 3 tissue sets. We observed significant differences in the location of mast cells in the ONT tissue set $(P<$ 0.0001 ), with nearly 4 times more mast cells observed in the near versus far stromal designations (Figure 5). However, differences in the number of mast cells in near versus far stromal regions were nonsignificant for both the $\mathrm{O} / \mathrm{I}$ and $\mathrm{E} / \mathrm{C}$ tissue sets. In mice, mast cells have been observed during postnatal development in the mammary stroma (Lilla and Werb, 2010). In the prepubertal gland, mast cells were observed scattered throughout, whereas mast cells were more frequently observed near TEB once the gland began to grow and proliferate (Lilla and Werb, 2010). The similarity in mouse and bovine mast cell localization, as evidenced by an increased concentration of cells in close proximity to developing ductal structures, suggest that bovine mast cells could also be involved in mammary develop- ment. Mice lacking stromal mast cells have fewer ducts ends at the invasive front, fewer TEB, and fewer proliferating cells (Lilla and Werb, 2010). This suggests that mast cells play a role in the extension of ducts into the mammary fat pad.

We also observed a trend for the effect of age in the ONT tissue set $(P=0.082)$ as well as a trend in the effect of estrogen treatment $(P=0.076)$ on mast cell numbers. These findings suggest that the number of mast cells change as the gland develops, which could be related to the relative rate of epithelial cell proliferation occurring in the developing ducts. The trend for an effect of estrogen treatment suggests that estrogen could have a role in mast cell regulation in the bovine mammary gland. Estrogen is known to increase bovine mammary ductal development (Woodward et al., 1993). Further work is required to determine if estrogen indeed does have an effect on numbers of immune cells in the stroma of the developing bovine mammary gland. 
Overall abundance (Figure 5) of mast cells was markedly greater in the youngest calves evaluated (ONT set). When averaged across tissue sets, number of mast cells in near stroma averaged $78.9 \pm 11.7,5.4 \pm 1.2$, and $7.6 \pm 2.2$ mast cells per millimeter squared for calves in the $\mathrm{ONT}, \mathrm{O} / \mathrm{I}$, and $\mathrm{E} / \mathrm{C}$ tissue sets, respectively, suggesting that mast cells are especially abundant in the mammary stoma of very young prepubertal calves. Indeed, given that numbers of mast cells were significantly different across tissue sets this suggests a general effect of age.

\section{CONCLUSIONS}

Overall, our findings suggest that all 3 immune cell types cluster closely with developing ductal structures in the developing bovine mammary gland suggesting that eosinophils, mast cells, and macrophages could be involved in bovine mammary development. These findings are in agreement with studies conducted in mice which also show an increased number of all 3 cell types near TEB during development. Especially striking was the 12.1-fold higher number of mast cells in mammary tissue from the youngest calves as compared with older animals. All 3 cell types have been shown to be essential to murine mammary development, and our data supports the concept that these immune cells also play a role in bovine mammary development.

\section{ACKNOWLEDGMENTS}

Archived tissues were derived from prior USDA, National Institute of Food and Agriculture, National Research Initiative (Washington, DC) competitive grants: (1) 2006-35206-6699, "Ovarian Regulations of Stem Cells and IGF-I Axis Molecules in Prepubertal Heifer Mammary Gland" to R. M. Akers and S. E. Ellis, and (2) USDA, NIFA, NRI 2009-35208-05778, "Myoepithelial Ontogeny in Prepubertal Heifers" to S. E. Ellis and R. M. Akers.

\section{REFERENCES}

Akers, R. M. 2002. Lactation and the Mammary Gland. 1st ed. Iowa State Press, Ames.

Capuco, A. V., R. K. Choudhary, K. M. Daniels, R. W. Li, and C. M. Evock-Clover. 2012. Bovine mammary stem cells: Cell biology meets production agriculture. Animal 6:382-393.

Capuco, A. V., S. Ellis, D. L. Wood, R. M. Akers, and W. Garrett 2002. Postnatal mammary ductal growth: Three-dimensional imaging of cell proliferation, effects of estrogen treatment, and expression of steroid receptors in prepubertal calves. Tissue Cell 34:143-154.

Chua, A. C., L. J. Hodson, L. M. Moldenhauer, S. A. Robertson, and W. V. Ingman. 2010. Dual roles for macrophages in ovarian cycleassociated development and remodelling of the mammary gland epithelium. Development 137:4229-4238.

Coussens, L. M., and J. W. Pollard. 2011. Leukocytes in mammary development and cancer. Cold Spring Harb. Perspect. Biol. 3:3.

Cunha, G. R., and Y. K. Hom. 1996. Role of mesenchymal-epithelial interactions in mammary gland development. J. Mammary Gland Biol. Neoplasia 1:21-35.

Geiger, A. J., R. E. James, C. L. Parsons, A. V. Capuco, and R. M. Akers. 2015. Growth, intake, and health of Holstein heifer calves fed an enhanced diet pre-weaning with or without exogenous estradiol immediately post-weaning. J. Dairy Sci. 98(Suppl. 2):528. (Abstr.)

Gouon-Evans, V., and J. W. Pollard. 2001. Eotaxin is required for eosinophil homing into the stroma of the pubertal and cycling uterus. Endocrinology 142:4515-4521.

Gouon-Evans, V., M. E. Rothenberg, and J. W. Pollard. 2000. Postnatal mammary gland development requires macrophages and eosinophils. Development 127:2269-2282.

Hovey, R. C., T. B. McFadden, and R. M. Akers. 1999. Regulation of mammary gland growth and morphogenesis by the mammary fat pad: A species comparison. J. Mammary Gland Biol. Neoplasia $4: 53-68$.

Ingman, W. V., J. Wyckoff, V. Gouon-Evans, J. Condeelis, and J. W. Pollard. 2006. Macrophages promote collagen fibrillogenesis around terminal end buds of the developing mammary gland. Dev. Dyn. 235:3222-3229.

Li, R. W., M. J. Meyer, C. P. Van Tassell, T. S. Sonstegard, E. E. Connor, M. E. Van Amburgh, Y. R. Boisclair, and A. V. Capuco. 2006 Identification of estrogen-responsive genes in the parenchyma and fat pad of the bovine mammary gland by microarray analysis. Physiol. Genomics 27:42-53.

Lilla, J. N., and Z. Werb. 2010. Mast cells contribute to the stromal microenvironment in mammary gland branching morphogenesis. Dev. Biol. 337:124-133.

Macias, H., and L. Hinck. 2012. Mammary gland development. Wiley Interdiscip. Rev. Dev. Biol. 1:533-557.

Purup, S., K. Sejrsen, J. Foldager, and R. M. Akers. 1993. Effect of exogenous bovine growth hormone and ovariectomy on prepubertal mammary growth, serum hormones and acute in vitro proliferative response of mammary explants from Holstein heifers. J. Endocrinol. 139:19-26.

Reed, J. R., and K. L. Schwertfeger. 2010. Immune cell location and function during post-natal mammary gland development. J. Mammary Gland Biol. Neoplasia 15:329-339.

Sheffield, L. G. 1988. Organization and growth of mammary epithelia in the mammary gland fat pad. J. Dairy Sci. 71:2855-2874.

Silberstein, G. B. 2001. Postnatal mammary gland morphogenesis. Microsc. Res. Tech. 52:155-162.

Tucker, H. A. 1981. Physiological control of mammary growth, lactogenesis, and lactation. J. Dairy Sci. 64:1403-1421.

Velayudhan, B. T., B. P. Huderson, M. L. McGilliard, H. Jiang, S. E. Ellis, and R. M. Akers. 2012. Effect of staged ovariectomy on measures of mammary growth and development in prepubertal dairy heifers. Animal 6:941-951.

Williams, J. M., and C. W. Daniel. 1983. Mammary ductal elongation: differentiation of myoepithelium and basal lamina during branching morphogenesis. Dev. Biol. 97:274-290.

Woodward, T. L., W. E. Beal, and R. M. Akers. 1993. Cell interactions in initiation of mammary epithelial proliferation by oestradiol and progesterone in prepubertal heifers. J. Endocrinol. 136:149-157. 